\title{
U.S. Survey on Provider Surveillance Patterns in Patients with Stage I Cervical Cancer After Cervical Conization
}

Silvana Pedra Nobre ${ }^{1}$, Varvara Mazina ${ }^{2}$, Yukio Sonoda ${ }^{1}$, Ginger J. Gardner ${ }^{1}$, Kara Long Roche ${ }^{1}$, Mario M. Leitao Jr ${ }^{1}$, Nadeem R. Abu-Rustum ${ }^{1}$, Jennifer J. Mueller ${ }^{1}$

${ }^{1}$ Memorial Sloan Kettering Cancer Center, Gynecology Service, Department of Surgery, New York, NY, USA

2University of Washington, Department of Obstetrics and Gynecology, Seattle, WA, USA

\section{BACKGROUND}

-Fertility-sparing treatment has been recognized as a feasible conservative approach in patients with early stage cervical cancer, and is an alternative treatment option for women wishing future pregnancy.

- Uniform guidelines on surveillance following fertility-sparing treatment of early stage cervical cancer focus on women who have undergone trachelectomy.

-Specific practice recommendations for surveillance of women who have been treated by cervical conization are lacking.

\section{OBJECTIVES}

-To characterize current practice patterns and identify practice variations in the surveillance of Stage I cervical cancer after cervical conization (CC) in the United States.

\section{METHODS}

-A 25-question RedCap ${ }^{\circledR}$ electronic survey was sent to members of the Society of Gynecologic Oncology. - Provider demographics, surveillance during first year (Y1) years 1-3 (Y1-3), and $>3$ years ( $\mathrm{Y} 3+)$ after $\mathrm{CC}$, and use of pelvic exam, cytology, HPV testing, colposcopy and endocervical curettage (ECC) were queried.

Figure 3: Practice Patterns in Completion

Hysterectomy after Cervical Conization other

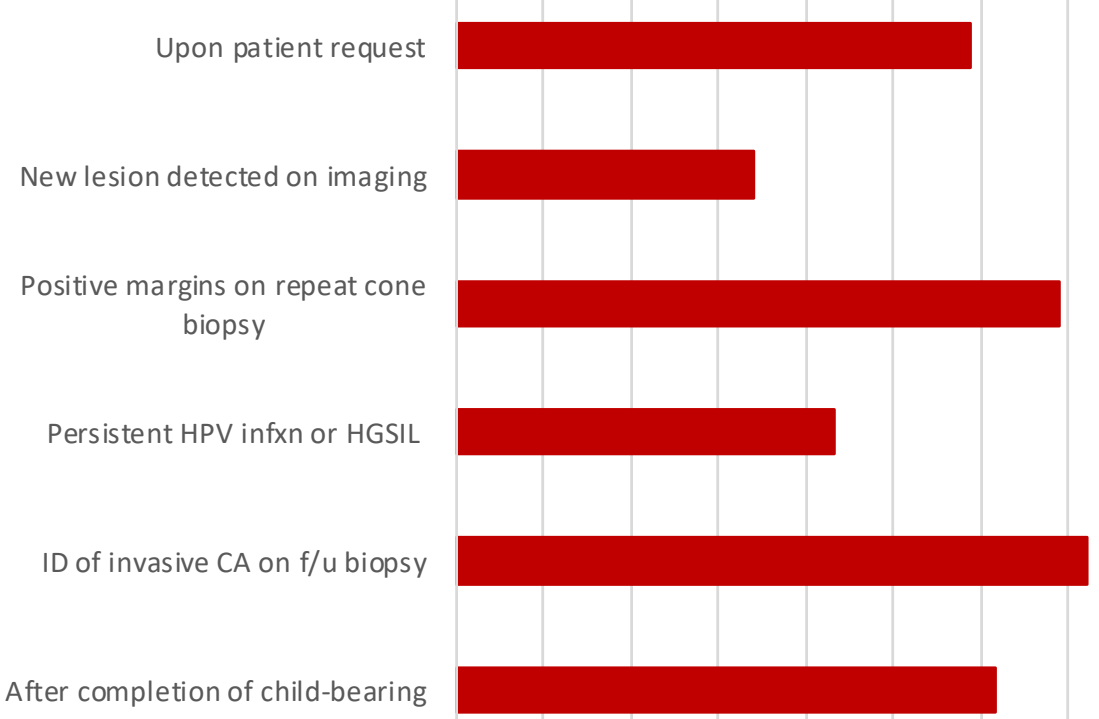

10\% $50 \% \quad 70 \% \quad 80 \% \quad 90 \% \quad 100 \%$ Years since completing fellowship

Figure 2: Surveillance Patterns in Stage I Cervical Cancer after Cervical Conization

\section{$90 \%$ Year 1, Years 1-2, >3 Years}

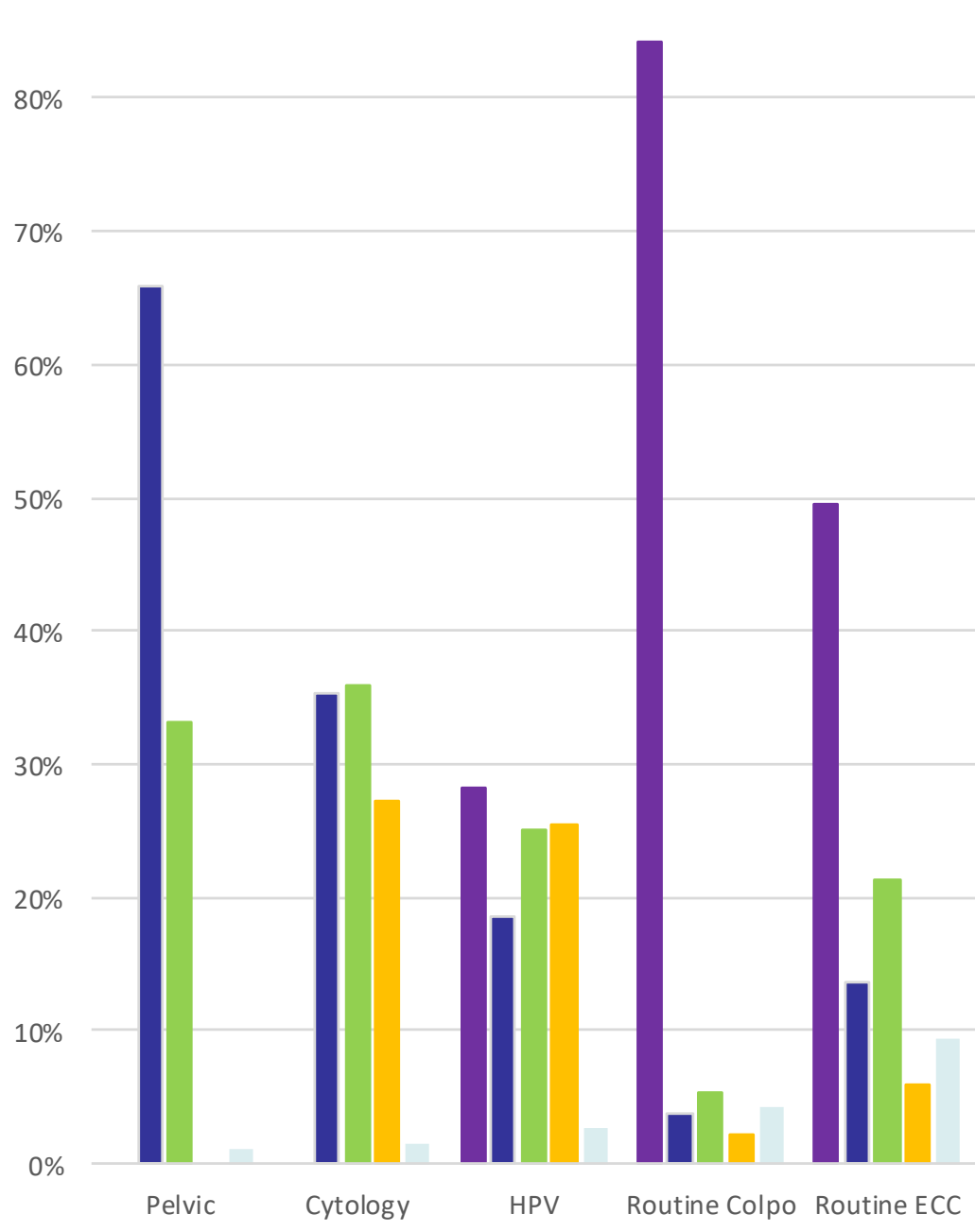

Y1 oncologists (Figure 1)

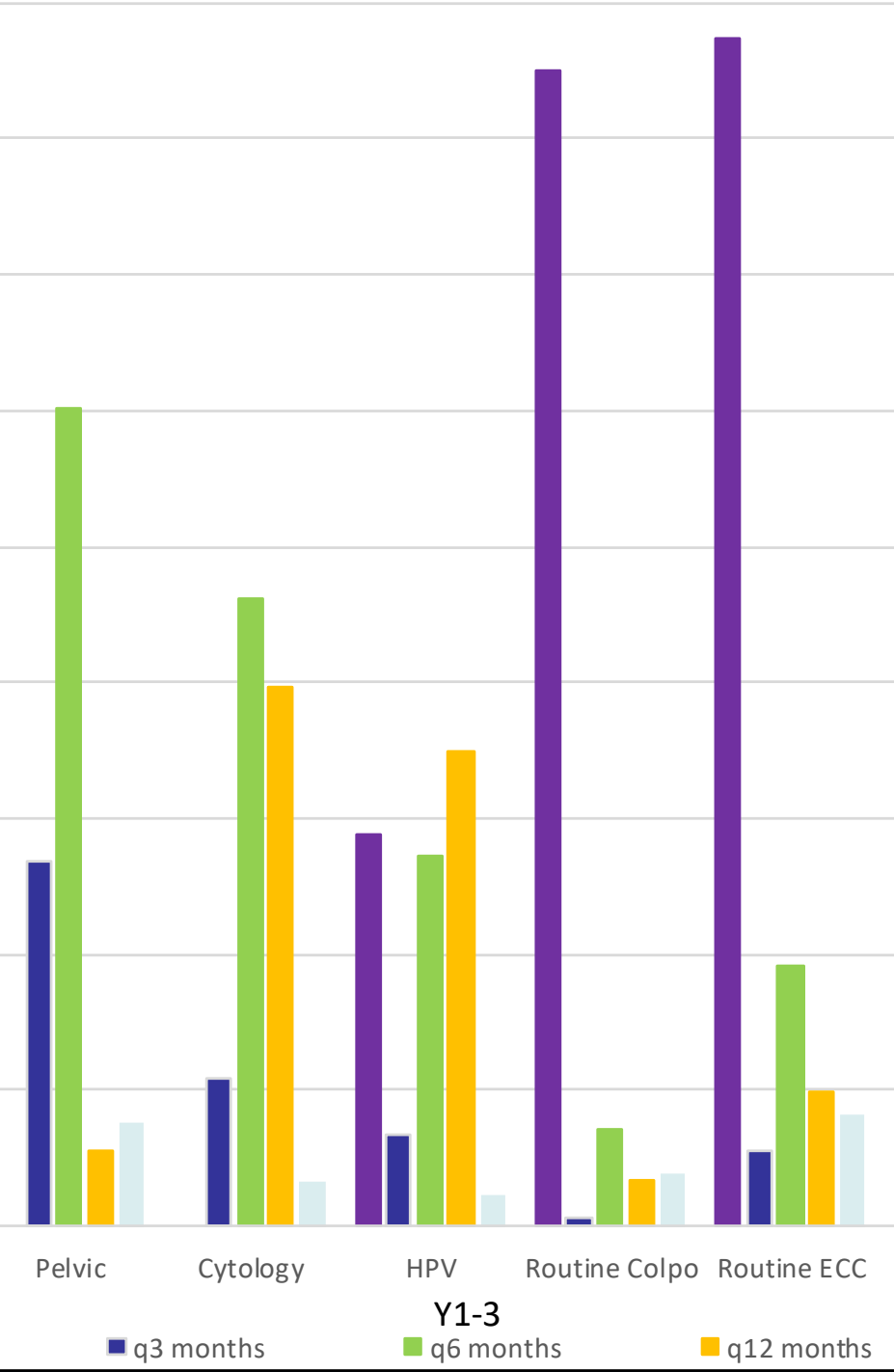

\section{RESULTS}

-185/1381 (13\%) responses were collected. All providers identified as gynecologic

- $11,66 \%$ of providers perform pelvic exam and $35 \%$ cytology q3 months (Figure 2).

- $Y 1-3,60 \%$ perform pelvic exam and $46 \%$ cytology $q 6$ months.

- $13+, 54 \%$ perform pelvic exam q6 months and $67 \%$ cytology annually.

- $28 \%$ of providers do not offer HPV testing at any point during 5-year follow-up. $52 \%$ recommend annual HPV testing Y $3+$ following CC.

- $86 \%$ of providers do not offer routine colposcopy and $71 \%$ do not offer ECC at any point during 5-year follow-up.

-75\% of providers screen patients for HPV vaccination.

-Surveillance results impact decisions for post-CC hysterectomy (Figure 3).

\section{CONCLUSIONS}

-There are no specific surveillance guidelines for Stage I cervical cancer treated with CC.

-The most commonly reported surveillance practice is q3 month pelvic exam with or without cytology in $\mathrm{Y} 1$ and $\mathrm{q} 6$ month thereafter.

-Wide variation exists in visit frequency, cytology and HPV testing, and there is a clear trend away from use of colposcopy and ECC.

-The disparities in these surveillance strategies suggest a need to define uniform surveillance guidelines for this unique patient cohort.

\section{Figure 1. Surveyed Provider Characteristics}

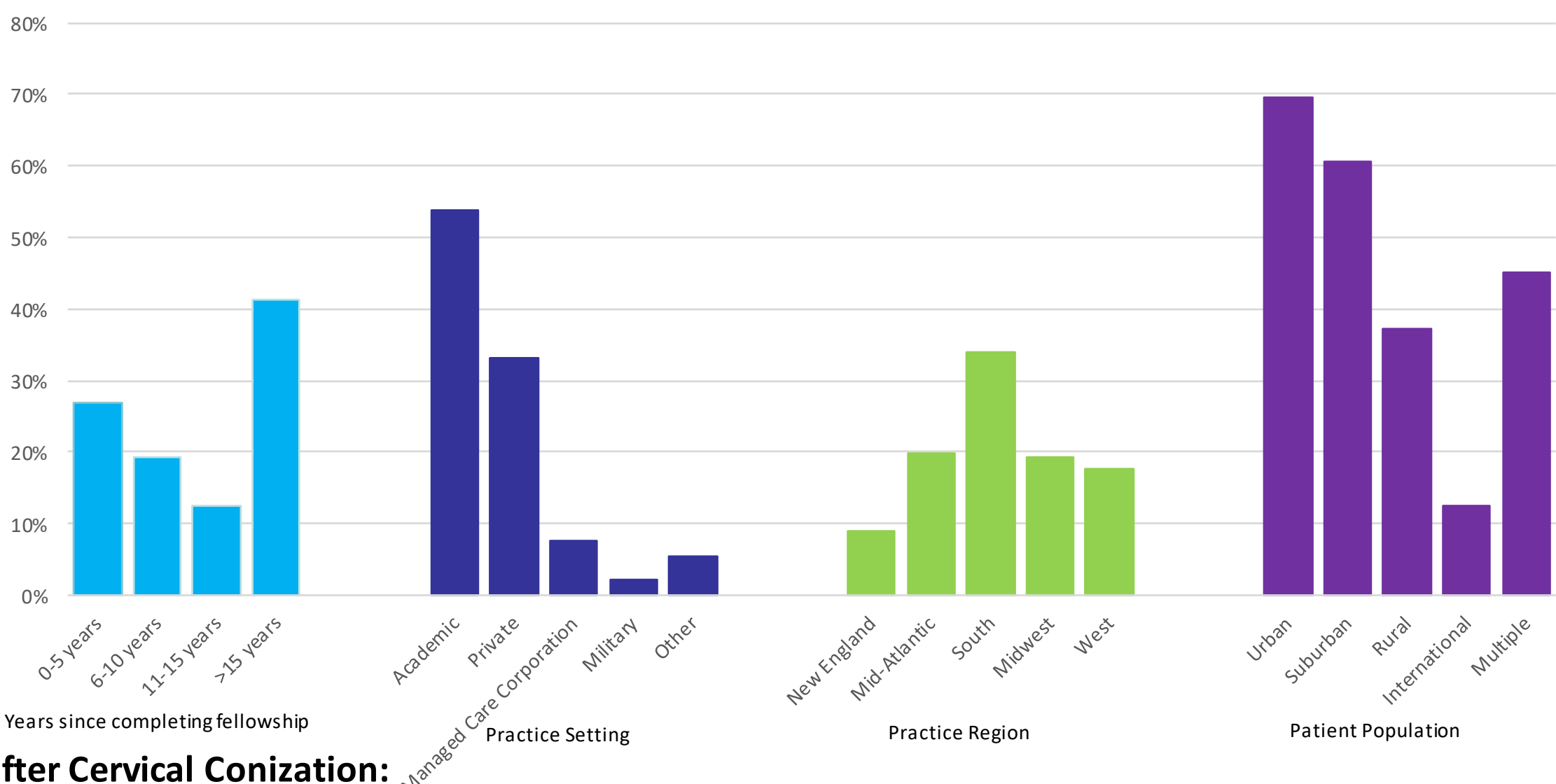

REFERENCES

Wright JD, Nathavithrana R, Lewin SN, et al. Fertility-conserving surgery for young women with stage IA1 cervical cancer: safety and access Obstet Gynecol 2010;115:585-590.

Koh WJ, Greer BE, Abu-Rustum NR, et al. Cervical cancer, version 2.2015. J Nat/ Compr Cancer Netw 2015;13:395-404. 